\title{
Interactions between Plastics, Microplastics, and Microbial Communities
}

\author{
Jingyi Yang ${ }^{1}$ and Kartik Chandran\# \\ ${ }^{1}$ Mercer Island High School, Mercer Island, WA, USA \\ \#Advisor
}

\section{$\underline{\text { ABSTRACT }}$}

Plastics have been an essential part of life. Each year, over 300 million tons of plastics are being processed each year into other products (Boucher and Friot, 2017). However, only a small portion of the plastic gets recycled while up to $79 \%$ is discarded into landfills or directly into the natural environment (Garcia and Robertson, 2017; Geyer et al., 2017). Microplastics refer to smaller plastic particles or pieces with a characteristic size less than 5 millimeters (NOAA, 2021). Primary and secondary microplastics either float in the ocean or sink and accumulate on the ocean floor depending on their weight (Eriksen et al., 2014; Sebille et al. 2015). Because of their small sizes, microplastics are able to pass through filtration systems and size-exclusion-based separation mechanisms. This allows them to remain in the environment for a longer period of time, harming microorganisms, marine life, animal life, and human life. Microorganisms have the ability to transform microplastics, and there have been numerous studies on the biodegradation of bio-based and fossil based plastics. This paper approaches the interactions of microplastics and microorganisms from three main angles - biodegradation, production, and impacts - by synthesizing and analyzing known information. In particular, biodegradability is linked to physical and chemical structures, while plastic polymers can be broken down into smaller compounds which can be potentially processed through bacterial metabolism to be ultimately mineralized as $\mathrm{CO}_{2}$ (Shah et al., 2008; Sangale et al., 2012; Devi et al., 2016). Compared to regular plastic, microplastics are more harmful and impactful to organisms (including humans), especially at the cellular level. The analysis of this paper is a good starting point for the investigation of microplastics and how microbial communities interact with them, however, it brings up further questions and gaps. Regardless, this paper highlights the significance of understanding the environmental, ecological and health implications of plastic and microplastic pollution.

\section{Introduction}

Plastics are such a big part of daily life, ranging from containers to buildings to vehicles to clothing. Its flexible usage and relatively cheap price make it extremely common. Over 300 million tons of plastics are being processed each year into other products (Boucher and Friot, 2017). The impacts of plastics are so prominent that researchers have coined terms like Plastisphere-a diverse microbial community found on microplastic surfaces, and Plasticene-the age of plastic in the current world (Zettler et al., 2013; Reed, 2016). With the amount comes problems like the disposal of the material. Jambeck et al. estimate that between 5 to 14 metric tons of plastic trash flow into the ocean every year (2015). It is reported that only 9 and $12 \%$ of global plastic wastes is recycled and incinerated, while up to $79 \%$ is discarded into landfills or disposed into the natural environment (Garcia and Robertson, 2017; Geyer et al., 2017). Plastic production contributes greatly to climate change, as it emits about 400 million tons of CO2 per year (Kaufman, 2018). The most common plastic present in waste, polyethylene, also emits methane, which is a highly potent greenhouse gas (Royer et al., 2018).

Microplastics are small pieces of plastic less than five millimeters long (NOAA, 2021). There are two types of microplastics: primary and secondary (Boucher and Friot, 2017). Primary microplastics are those that are directly released into the environment or formed from the abrasion of larger plastics in the manufacturing products, while 
secondary microplastics originate once larger plastic items are exposed to the marine environment (Boucher and Friot, 2017). An estimate of 93 to 268 ktons of microplastics are floating in the ocean (Eriksen et al., 2014) (Sebille et al. 2015). Other microplastics that are heavier than seawater sink and accumulate on the ocean floor.

Since the size of microplastics allows them to pass through filtration systems, they end up in various water bodies and are very harmful to aquatic life. Marine biota like corals, phytoplanktons, sea urchins, lobsters, fish, etc. mistake microplastics as food and ingest them (Chatterjee and Sharma, 2019). Microplastics are then transferred to higher trophic levels through biomagnification. Human health concerns are also reported because of the accumulation of microplastics in the food chain as well as toxicants of plastics while they travel through the environment (Eriksen et al. 2014). Microplastics are also not visible to the human eye, therefore their impacts are less obvious.

Marine microbes are marine organisms that are smaller than $0.1 \mathrm{~mm}$ while the smallest well-known marine microorganism Candidatus Pelagibacter ubique HTCC1062 measures at 0.5 x $0.15 \mu \mathrm{m}$ (Glöckner et al., 2011). The diversity of marine microbes is evident in the fact that they belong to both the prokaryotic (bacteria) and eukaryotic (fungi, protists) branches on the tree of life. They make up $98 \%$ of the biomass of the world's ocean, supply the world's oxygen, and can process greenhouse gases (AIMS, 2021). These organisms and assemblages mediate cycling and reactions of different elements $(\mathrm{C}, \mathrm{N}, \mathrm{P}$, and others) at a global scale; however, they are being impacted by global climate change events. For example, higher levels of $\mathrm{CO} 2$, which causes ocean acidification, affect the relationship between the photosynthetic bacterium Prochlorococcus and its helper bacterium Alteromonas (Tsang, 2020). Microplastics are known to negatively influence sediment-associated microbial communities and nitrogen cycling. Seeley et al. have explored the effects of microplastics on the structure and function of microbial communities in coastal salt marsh sediments (2020). Their results indicate that bacterial diversity is the lowest in polyethylene amended sediments while community composition over time exhibited the most variation for polyethylene-amended sediments (Seeley et al., 2020).

Microorganisms, on the other hand, also have the ability to transform microplastics. According to Rogers et al.'s study, pelagic and benthic microbial communities associated with microplastics can affect their ingestion and transfer in the food webs (2020). Certain bacteria and fungi have the ability to biodegrade plastics, although they are not a viable and reliable source to remediate or recycle plastics.

This paper aims to fill in the gaps of knowledge present regarding the interactions between microplastics and marine microbial communities by synthesizing and analyzing known information. We arrive at three central questions: (1) what different types of organisms are known to break down microplastics, and what is the relationship between a plastic's degradability and its durability, which is defined by its physical and chemical properties. (2) What are the challenges associated with microplastic bio-production, and what are the common biological structures and functions associated with microplastic bio-production. (3) How do microplastic impact biological systems and the environment? How do these impacts influence human society? We intend to incorporate the biodegradability and bioproduction of microplastics from various literature sources, and aim to deduce the viability and importance of these techniques for their impact on our global environment.

\section{Biodegradability}

\section{Impact of physical and chemical structure on the biodegradability of plastics}

The term bioplastics is oftentimes associated with biodegradability. However, it isn't entirely this simple. Bioplastic is a broadly-encompassing term for biodegradable plastics or bio-based plastics. The difference between the two is that biodegradable plastics refers to those that can be assimilated by bacteria and/or fungi (but can refer to plastics produced from fossil materials) while bio-based plastics are synthesized from biomass or renewable resources (Tokiwa et al., 2009; Filiciotto and Rothenberg, 2020). There could also be plastics that are identified in both groups. 


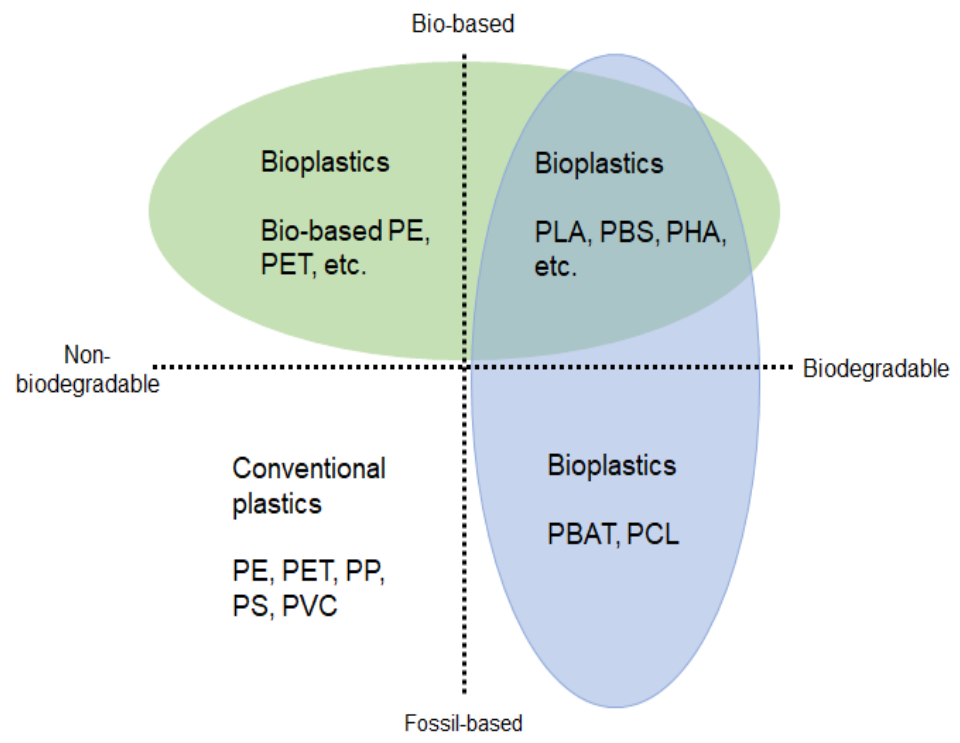

Figure 1. Different types of plastics categorized as bio-based (top), fossil-based (bottom), biodegradable (right), nonbiodegradable (left), or both bio-based and biodegradable (top right). Figure was adapted from https://www.europeanbioplastics.org/bioplastics/.

Both the chemical and physical properties of plastics can influence their biodegradability. Biodegradability also varies depending on environmental factors such as humidity, temperature, and oxygen (Filiciotto and Rothenberg, 2020). Bio-based plastics that are not biodegradable are usually structurally similar to petroleum-based plastics.

Physically, the bigger the surface area of the plastic, the greater its biodegradation (typically proportional) (Filiciotto and Rothenberg, 2020). Usually, microbes are drawn to hydrophilic surfaces, so plastics with similar properties may undergo higher biodegradation rates. Therefore bio-based plastics containing heteroatoms are more biodegradable (Shah et al., 2014). In addition, higher crystallinity and molecular weight can reduce biodegradability (Filiciotto and Rothenberg, 2020). Branching could improve bio-assimilation but does not guarantee it (Gewert et al., 2015).

Chemically, the presence of oxygen-containing groups like ester, acid, alcohol, and aldehyde is an enhancer to biodegradation because it improves the polar interaction with water (Okey and Stensel, 1996). Another factor that favors biodegradability is the introduction of amine or amide groups (Ebbesen et al., 2016; Luo et al., 2011). Okey and Stensel also found that the carboxyl group enhanced the rate significantly while the hydroxyl group did not have a big impact (Okey and Stensel, 1996). On the other hand, halogenation can decrease bio-assimilation due to their toxicity and aliphatic groups are a barrier because of their general low reactivity (Boethling et al., 2007). The presence of aromatic groups reduces biodegradability but the addition of aliphatic esters can improve the process (Gewert et al., 2015; Shah et al., 2014).

Enzymatic degradation involves two important processes that can be measured by weight loss and additions of functional groups (Aristilde, 2017). In Mohanan et al.'s study, they examined the various enzymes expressed by microbes that have the ability to degrade petro-polymers under in vitro conditions (2020). The enzymatic degradation occurs in two stages, which are adsorption of enzymes on the polymer surface and hydro-peroxidation/hydrolysis of the bonds (Mohanan et al. 2020).

There is a wide range of organisms capable of microplastic biodegradation. Notably, the genus Amycolatopsis has been associated with breaking down poly-lactic acid (PLA) films (Ikura and Kudo, 1999; Pranamuda et al. 1997). PLA is considered a viable option for renewable plastics due to its make-up of lactic acid, which can serve as a carbon source for certain bacteria species such as Amycolatopsis sp. Furthermore, its high melting point (180 C) and easy manufacturing is suitable for plastic production and distribution. Studies have shown that PLA can be subject to 
biodegradation at different temperatures $(30 \mathrm{C}$ or $43 \mathrm{C}$ ) by the same genus of Amycolatopsis, but the rate of its degradability can be dependent on a variety of factors such as temperature, nutrient content, and type of PLA film. Conceivably, higher temperatures $(43 \mathrm{C})$ enable a faster rate of biodegradation, but a low concentration $(0.002 \%)$ of yeast extract in the cultures can stimulate the degradation process while a high concentration $(0.02 \%)$ may impede it. Additionally, PLA containing certain percentages of D-type isomers or chemicals such as glycolic acids may be degraded more easily and rapidly than the 100\% L-type PLA that is conventionally manufactured (Ikura and Kudo 1999). The caveat to PLA production lies in the fact that it cannot yet be produced cheaply, and thus still has yet to replace the major commercial plastics that are less biodegradable.

In other circumstances, certain phytopathogens such as fungi can break down polycaprolactone (PCL), a synthetic polyester that can be used as an alternative to the major commercial plastics such as polypropylene, polystyrene, and polyvinyl chloride. The enzymes and substrates by which organisms use to break down and grow on PCL are still largely unknown, but studies have found that the fungus Fusarium moniliforme may utilize PCL depolymerase to degrade cutin, a structural polymer of the plant cuticle, and potentially a chemical intermediate with which $F$. moniliforme may grow on and use as a carbon source (Murphy et al. 1996). Another study found that the yeast Pseudozyma japonica is also capable of PCL as well as polystyrene degradation, and achieved a maximum weight loss of $93.33 \%$ of PCL (70,000 - 100,000 Daltons) film in 15 days (Abdel-Motaal et al., 2013). Nevertheless, PCL's high biodegradability is also overshadowed by its less functional physical properties, with its low melting point (62 C) a problematic barrier to many applications (Murphy et al. 2012; Murphy et al. 1996).

PLA and PCL are some of the main representatives of commercially produced polyesters, but their applicability is hindered by either their cost of production and/or their poor mechanical properties, respectively. Polybutylene succinate (PBS), therefore, may provide for a polyester alternative that is both cheap to synthesize and also adequate in mechanical properties. With a high melting point of $(115 \mathrm{C})$, it is characteristically broken down through composting (Zhao et al. 2005). A diverse set of compost organisms can be used for the biodegradation of PBS, namely Aspergillus versicolor, Penicillium, Bacillus, and Thermopolyspora. However, the rate at which PBS is broken down is largely dependent on its structure and surface area. A study (Zhao et al. 2005) conducted under controlled composting conditions (58 C) found that PBS powder in liquid medium had the highest rate of biodegradation compared to its other forms (film and granule). It is likely that the powdered PBS dissolved in chloroform and precipitated in methanol provided for a larger and rougher surface with which microorganisms may favorably adhere to. Contrary to PCL, there is no specific biodegradation enzyme for PBS, and is gradually degraded by lipases into CO2 or metabolites (Kunioka et al., 2009).

Durability is an important factor to plastic usage. Polyethylene, a thermoplastic with high durability, is considered the most widely used plastic today. Such high durability correlates to a low degradability in the environment, and allows polyethylene materials to persist and accumulate at an alarming rate. Recently, however, studies have found specific strains of bacteria capable of degrading low-molecular-weight polyethylene (LMWPE) or low-density polyethylene (LDPE). A thermophilic bacterium, Chelatococcus sp. E1, was isolated from compost and identified as being able to break down LMWPE at a temperature of $58 \mathrm{C}$ (Jeon and Kim 2013). Interestingly, the microbe exhibited preferential assimilation of the low-molecular-weight fractions of the LMWPEs, as higher molecular weight was consistent with lower degradability. One caveat to LMWPE biodegradation is that it needs to be prepared from the thermal degradation of HDPE or LDPE under strict circumstances, the complexity in this process should be further investigated to examine its effects on a commercial scale. Hence, another bacterium, Pseudomonas sp. AKS2, is capable of breaking down LDPE at $30 \mathrm{C}$ without any prior oxidation process (Tribedi and Sil 2013). It is common knowledge that polyethylene materials are hydrophobic, which prevent adhesion to their surfaces as most bacteria have hydrophilic surfaces. However, Pseudomonas sp. AKS2 shows increased attachment to LDPE due to its similarly hydrophobic nature, allowing it to partially degrade the plastic. Furthermore, bacterial biofilms have been shown to enhance biodegradability of polyethylene, as the prevention of biofilm formation lowers the rate of LDPE degradation. Therefore, the use of mineral oils, which can not only increase bacterial attachment to the plastic surface but also stimulate biofilm formation, has been found to significantly enhance LDPE degradation rates. However, the use of mineral oils 
has only been studied under controlled laboratory conditions, but its applications to a broader scale in the environment is limited by our current knowledge gap.

Like polyethylene, polypropylene (PP) is another synthetic polymer that is recalcitrant to degradation in nature, but has appreciable physical properties that make it widely applicable. However, different microbial species have been found to break down PP at an extended amount of incubation time (Cacciari et al., 1993). The study identified Enterobacteriaceae and other gram negative bacteria as capable of degrading PP at $30 \mathrm{C}$. Through aerobic and anaerobic degradation, the bacterial community degraded 40\% of PP in 175 incubation days, producing hydrocarbons and aromatic esters as metabolic byproducts of the degradation process. Ultimately, the study thus showcased a coexistence of aerobic and anaerobic species in the biodegradation process, despite their different catabolic activities. This is one of the more significant discoveries of metabolic plasticity and its important role in biodegradation of the recalcitrant polymer polypropylene.

Another hydrophobic plastic, polystyrene (PS), is also a widely used and durable thermoplastic thought to be non-biodegradable. The actinomycete Rhodococcus ruber (C208) has been shown to partially degrade polystyrene under favorable conditions (Mor and Sivan, 2008). Similar to polyethylene biodegradation, the formation of C208 biofilms was stimulated with an addition of mineral oil and correlated with enhanced degradation of polystyrene flakes. Interestingly, polystyrene can serve as not only the substrate but also the carbon source for C208 specifically, suggesting that carbon starvation experiments in which polystyrene is the sole source of organic carbon may enhance biofilm development in this bacterial strain. It seems likely that Rhodococcus bacteria under low carbon conditions are likely to exhibit higher hydrophobicity and affinity for non-degradable plastics such as polyethylene and polystyrene, using them not only to as adhesive surfaces but also carbon sources (Sanin et al., 2003; Sivan et al., 2006).

Polyurethane (PUR) is another synthetic polymer that is known to withstand biodegradation. It is commonly found that the polyester-type PURs are more degradable than the polyether-type PURs in fungal degradation studies (Darby and Kaplan, 1968). More recently, bacteria such as Comamonas acidovorans strain TB-35 has been shown to degrade the polyester-type PUR using it as both a carbon and nitrogen source (Nakajima-Kambe et al. 1995). The study integrated PUR into a basal medium and incubated at $30 \mathrm{C}$. After 7 days, it was found that PUR was completely degraded when it was supplied as the sole carbon source, and was $48 \%$ degraded when supplied as both the carbon and nitrogen sources. High-performance liquid chromatography (HPLC) analysis showed peaks corresponding to diethylene glycol and trimethylol-propane as breakdown products when PUR was supplied as the sole carbon source, while an additional product - adipic acid - was found when PUR was the sole carbon and nitrogen source. The high rate of PUR degradation here should be observed with more caution, as while TB-35 was not able to grow without PUR in the study, it was still amended with a basal medium that supplied other forms of nutrients.

Similarly, polyvinyl chloride (PVC) is one of the main synthetic plastics noted for its recalcitrant characteristics. However, as indicated previously, Pseudomonas spp. have been widely studied for their ability to degrade otherwise non-degradable polymers. A study recently discovered the biodegradation of PVC film by Pseudomonas citronellolis at $30 \mathrm{C}$ under aerobic conditions (Giacomucci et al., 2019). The study specifically determined a 13.90 +/$6.84 \%$ weight loss in the virgin PVC film in 30 days of incubation, but also found that waste PVC films underwent higher biodegradability in the same time frame. Furthermore, the study examined the possibility of biofilm production during the degradation process, and recorded higher expression of adherent and ribosomal proteins at 45 days into the incubation, suggesting that biofilm production was highest during this stage of the incubation. While it is often found that Pseudomonas is capable of degrading various polymers, the study indicated that another bacterium - Bacillus flexus - may also break down PVC under controlled aerobic conditions. It is thus imperative to factor in other types of organisms in our search for optimal biodegradation rates. How each organism responds and utilizes the specific polymer should be subject to further investigation.

Biological degradation and metabolism have the potential to eliminate plastics from contaminated environments (Kovenbach et al., 2014). The structure of the polymer surface determines the ability of bacterial cells to degrade plastic (Donlan, 2002). The nutritional value of the environment may influence the extent of the biofilm formation (Sivan, 2011). Additionally, plastic polymers can be broken down into smaller compounds, some of which can be 
potentially processed through bacterial metabolism (Shah et al., 2008; Sangale et al., 2012; Devi et al., 2016). Our literature review has provided us with a better understanding of the different organisms that are capable of breaking down respective plastics (table 1). Of the major plastics, polyurethane, polylactic acids, and polycaprolactone seem to be the most biodegradable but also the least commercially applicable. On the other spectrum, polypropylene, polyethylene, and polystyrene exhibit the lowest biodegradation rates but are highly durable in their physical and chemical properties (Fig. 2). Nevertheless, the rate of biodegradation for different plastics vary drastically and are influenced by many abiotic factors.

\begin{tabular}{|l|l|l|}
\hline Plastic & Organism(s) & Source \\
\hline Polyurethane (PUR) & Comamonas acidovorans (TB-35) & Nakajima-Kambe et al. 1995 \\
\hline Polyactic Acids (PLA) & Amycolatopsis sp. & Ikura and Kudo 1999 \\
\hline Polyacaprolactone (PCL) & Pseudozyma japonica & Abdel-Motaal et al. 2013 \\
\hline Polybutylene (PBS) & Aspergillus versi- color, Penicillium, Bacillus, and Thermopolyspora & Zhao et al. 2005 \\
\hline Polyethylene (LMWPE) & Chelatococcus sp. E1 & Jeon and Kim 2013 \\
\hline Polyvinyl chloride (PVC) & Pseudomonas citronellosis & Giacomucci et al. 2019 \\
\hline Polypropylene (PP) & Enterobacteriaceae & Cacciari et al. 1993 \\
\hline Polyethylene (LDPE) & Rhodococcus ruber & Sivan et al. 2006 \\
\hline Polystyrene (PS) & Rhodococcus ruber (C208) & Mor and Sivan 2008 \\
\hline
\end{tabular}

Table 1. A compiled summary of the aerobic microbes and their respective biodegradable plastics, as referenced through our literature review.

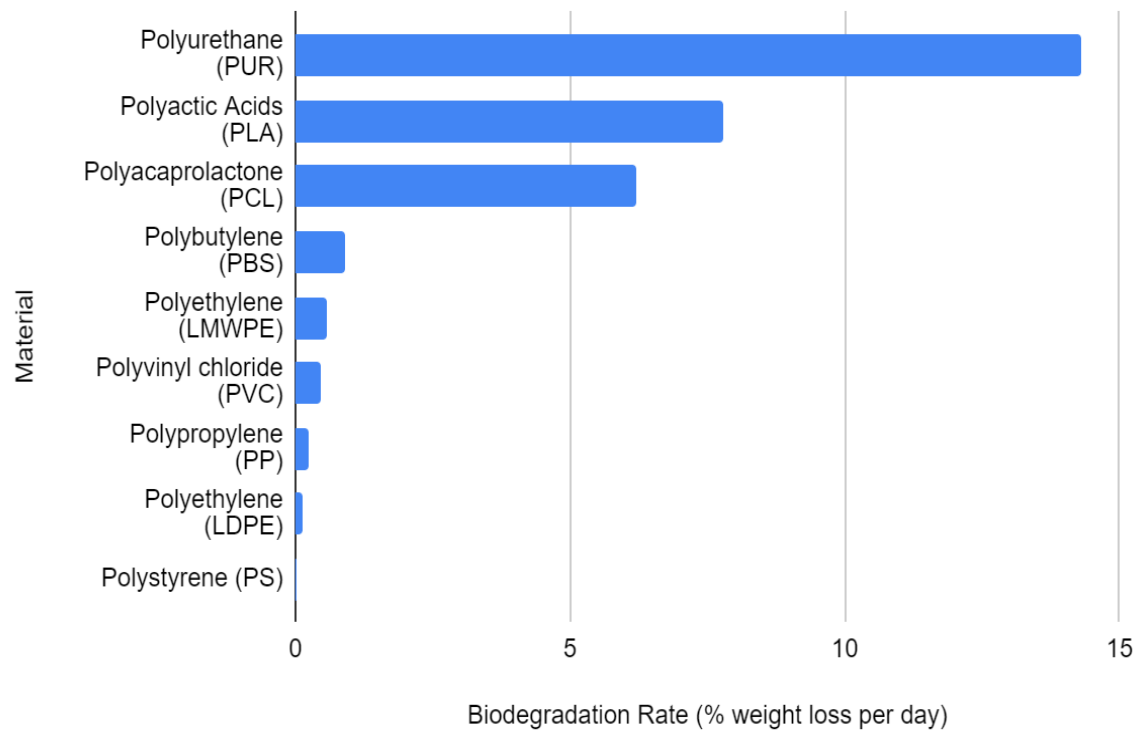

Figure 2. Bar plot of the different types of plastics and their respective biodegradation rates in percentage weight loss per day. Rates were compiled from different literature focused on the respective plastic material and its degradability under different microorganisms as according to the references in table 1.

\section{Production}

Bioplastics are an innovative solution to reduce the pollution of plastics. Bio-based plastics are gaining in popularity as an alternative to fossil-based plastics (Cinar et al., 2020). However, as outlined in the previous sections of the paper, 
there are nuances for bioplastics as well. This section aims to explore the different ways of bioplastic production and examine their merits.

Bio-based plastics are classified into three categories, which are modified natural polymers, synthesized biobased polymers from synthesized bio-based monomers, and bioplastics from waste (Thielen, 2014). As of 2020, bioplastics make up approximately one percent of plastic produced annually. However, bioplastic production is set to increase from 2.11 million tonnes in 2020 to about 2.87 million tons in 2025 according to the market data compiled by European Bioplastics and the nova-Institute (European Bioplastics 2020). Currently, the main applications of bioplastics include the packaging industry, the textile industry, the automotive industry, and construction (Alaerts et al., 2018). The sources used for bioplastic production include plant-based raw materials, natural polymers (carbohydrates, proteins, etc.), and other small molecules (sugar, disaccharides, and fatty acids) (Thielen, 2014).

Currently, most bioplastics are produced from agricultural crops that are rich in carbohydrates (Karan et al., 2019). The sources of bioplastics include a vast range of carbohydrate-rich feedstock like sugarcane, corn, sugar beet, and cassava (Lovett and de Bie, 2016). In which raw sugar extracted from sugarcane or dextrose from corn starch are the main feedstocks used today to produce lactic acid and its derivatives (Lovett and de Bie, 2016). Monomers and polymers like polylactic acid (PLA), cellulose, renewable polyethylene, and polyvinyl chloride (PVC), can be sourced from higher plant crops (Karan et al., 2019). For example, PLA is based on lactic acid and is mainly produced by the fermentation of sugar or starch with the help of microorganisms (Thielen, 2020). Polyethelyenterephthalat (PET) is produced using monoethylene glycol, which is obtained from sugar cane molasses, and terephthalic acid (Thielen, 2020). Polybutylene succinate (PBS), a biodegradable bioplastic, is produced from butanediol, which is produced from renewable resources such as maize starch, and succinic acid, which can be produced by fermentation from starch and different oligosaccharides (Thielen, 2020). However, Bioplastics derived from terrestrial and agricultural crops compete with food supplies or use up large amounts of water, land areas, and nutrients (Cinar et al., 2020). Bioplastics from crops are also shown to be unsustainable long-term (Cinar et al., 2020). In the future, it is predicted that forestry will play an increasingly important role as a raw material supplier for bio-based plastics, as the use of cellulose and lignin does not compete with food and animal feed supplies (Thielen, 2020). On the other hand, there are also reports showing that the land use for bioplastic production is minimal and does not compete with the land used for food (Lovett and de Bie, 2016).

Bioplastics from microalgae, on the other hand, are much more sustainable. Microalgae-based bioplastics can be designed for biodegradability in natural as well as industrial settings (Karan et al., 2019). Internationally, this technique could offer the capacity to support distributed production, while locally it can enable regional communities to be more self-sufficient (Karan et al., 2019). Photosynthetic organisms like microalgae can grow and produce feedstocks using inorganic materials such as nitrogen and phosphate (Nakanishi et al., 2020). The system using microalgae has the advantage of producing resources for bioplastics because microalgae can be cultivated in fresh water and seawater instead of terrestrial cropland (Kaparapu, 2018; Machmud et al., 2013).

The other option is to generate bioplastics using residual and waste materials. Perotto et al. have found a way to fully convert a variety of vegetable waste materials (like carrot, parsley, radicchio, and cauliflower) into bioplastic film in one step (2018). The flexible bioplastic films were produced without environmental concerns and are completely biodegradable (Perotto et al., 2018). Another option of using waste material to produce plastics is using the potato peel from the french fries industry and processed water high in starch. In New Zealand and the Netherlands, municipal wastewater serves as the source for PHA-producing bacteria (Thielen 2020). Non-food biomass crops, agricultural byproducts, and waste streams are also alternative feedstocks, while specific examples include miscanthus, wheat straw, bagasse, corn stover, and wood chips (Lovett and de Bie, 2016).

\section{Bacterial production of PHAs}

In relation to bacterial plastic bioproduction, Polyhydroxyalkanoates (PHA) and more specifically Poly- $\beta$-hydroxybutyrates (PHB) are the main polymers synthesized by microorganisms which are fully degradable. More importantly, these PHAs are thermomechanically similar to the conventional plastics such as polypropylene, but are unique in the 
sense that they can be $100 \%$ broken down into water and carbon dioxide through aerobic degradation and methane through anaerobic degradation. PHB is the most widely studied form of PHA, and its stiff and crystalline structure contributes to its brittleness. Its melting point (175C) is also only slightly lower than the temperature at which it is degraded by crotonic acid. These poor physical properties make PHB processing quite difficult, and has led to the study of other copolymers with better properties (Khanna and Srivastava, 2005).

Nevertheless, the biological properties of PHA synthesis in microorganisms must be taken into account. Ralstonia eutropha, is a gram-negative bacterium capable of accumulating PHB from simple carbon sources such as glucose, fructose, and acetic acid. However, it belongs to a group of bacteria that require nutrient limitation of nitrogen, phosphorus, magnesium, or sulfur in order to synthesize $\mathrm{PHB}$, with potential for a high production rate of 2.42 (g/l/h) when glucose is utilized as the carbon source (Kim et al., 1994) (Fig. 3). Alicaligenes Latus is one bacterium that does not require any nutrient limitation during PHA production, and is able to use cheap $\mathrm{C}$ resources such as glucose and sucrose to produce PHB at a rate similar to that of $R$. eutropha. Certain strains of $A$. latus may also be used to produce PHB from molasses or sugar syrup at an approximate PHB productivity rate of $1.15(\mathrm{~g} / \mathrm{l} / \mathrm{h})$ through a fed-batch fermentation process (Grothe and Christi, 2000) (Fig. 3). PHA may also be synthesized by methylotrophs, in which the use of methanol as the growth substrate may reduce the cost of production. The methylotroph Protomonas extorquens has been shown to produce PHB from this cheap carbon source, but its low production rate of 0.88 (g/l/h) will require further experimentation that may enhance productivity in the future (Suzuki et al., 1986). PHA production by Pseudomonas oleovorans has also been documented, yielding lower productivity values of 0.58 (g/l/h) through the fedbatch continuous culture process (Preusting et al., 1993). Lastly, recombinant Escherichia coli harboring PHA biosynthesis genes have also been studied and used in experimentation, where a PHB productivity of 2 (g/l/h) has been observed in pH-stat fed-batch cultures (Kim et al., 1992) (Fig. 3). However, the high oxygen demand during the fermentation process needs to be addressed in order to apply it on an economical and commercial level.

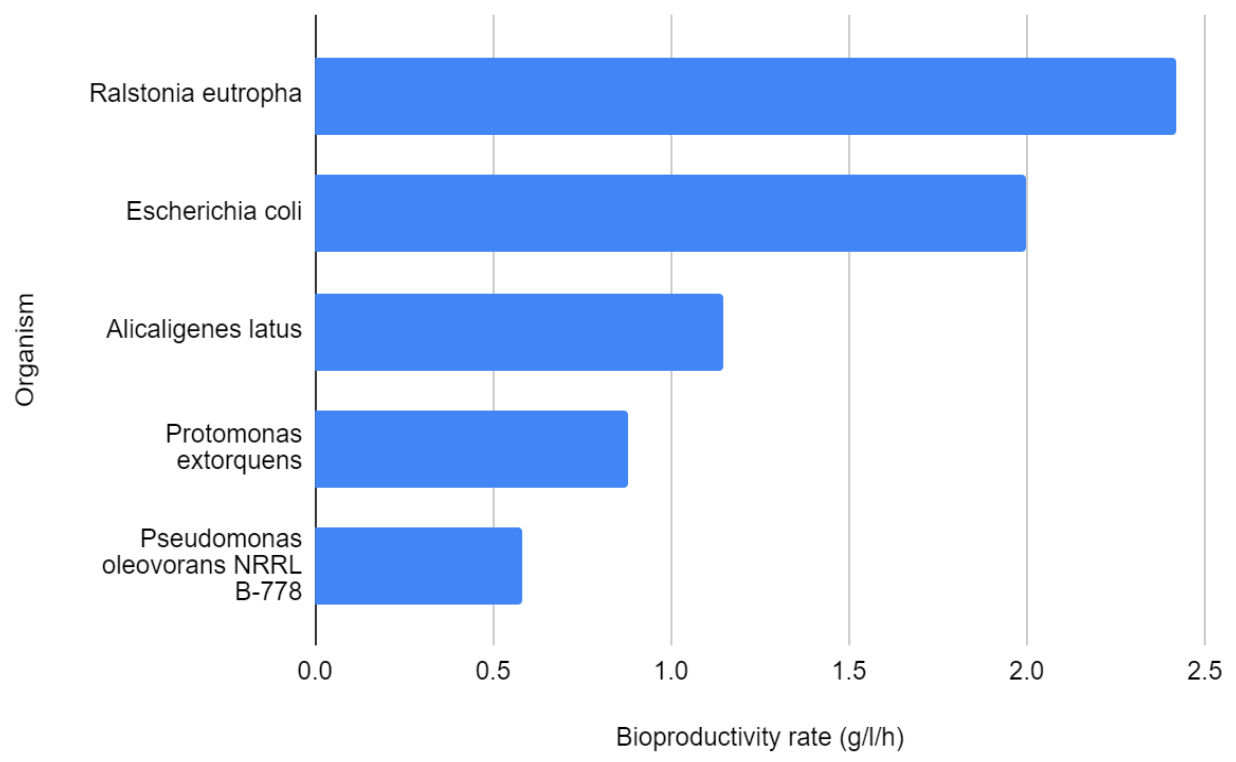

Figure 3. PHA/PHB productivity rates $(\mathrm{g} / \mathrm{L} / \mathrm{h})$ of different wild-type and genetically engineered microorganisms that are able to synthesize and accumulate polymers. Data was derived from our literature review of the different organisms and their bioproductivity rates, references are included in the text.

Multitudes of microorganisms have been implicated in the biosynthesis of PHAs and PHBs. Their ability to thrive on simple forms of sugar as their carbon sources and enhanced accumulation of these hydroxyalkanoates may have a profound impact on our understanding of plastic production. Yet, due to the high cost of PHA synthesis, it hasn't made an impact on the commercial scale. The underlying biosynthesis pathways of plastic production must be 
coupled with the culturing applications in order to broaden our scope of understanding PHA production in microbes. In this sense, the use of genomic tools such as metabolic engineering may unlock the potential for these polymers to be produced on an economic level. Future studies should focus on such novel techniques to enhance productivity rates and contribute to the advancement of knowledge that may one day bring about the feasibility of commercially producing fully degradable plastics.

\section{Impacts}

\section{Microplastics are inherently more harmful than other plastics due to their size}

In sedimentary microbial communities, microplastics are particularly abundant because of land runoff, poor waste management, storm drains and sewage overflows, and wastewater treatment plant outfalls (Seeley et al., 2020). Seeley et al.'s study also reveals that microplastic contamination affects both composition and function of sediment microbial communities (2020). They found that the PVC treatment inhibits both nitrification and denitrification.

Researchers that collected sediment samples from the Huangjinxia Reservoir in China have found that the different microplastic concentrations might have affected the microbial communities and their diversity in the sediments ( $\mathrm{Li}$ et al., 2020). They also found a significant impact on the structure of the microbial community (Li et al., 2020). Microplastics can produce toxic substances such as phthalates during the degradation process, which have a toxic effect on microorganisms (Di and Wang, 2017). Mughini-Gras et al. identified microplastics and microbial communities in samples from the Rhine River and found that microbial composition on microplastics 100-500 $\mu \mathrm{m}$ differed significantly from 10-100 $\mu \mathrm{m}$ (2020). Additionally, as particles become smaller, the microbial community was observed to be more "water-like" (the surface water) (Mughini-Gras et al., 2020).

For marine organisms, global plastic pollution has great impacts on their lives. Eighty-eight kilograms of plastic waste caused the death of a Cuvier's beaked whale in the Philippines and $220 \mathrm{~kg}$ of refuse showed up in the necropsy of a young sperm whale on a Scottish beach (Borunda, 2018; Beachum, 2019). Microplastic has direct negative impacts such as entanglement, ingestion, smothering, hangers-on, hitch-hiking, and alien invasions on organisms in aquatic systems (Gregory. 2009). Microplastics consumed by the lower levels of the food chain can also move up to pose threats to species not in the ocean.

Plankton, the most essential element of marine habitat, are adversely affected. Zooplankton in particular, are found to interact with microplastics the most since they are similar in size (Cole et al., 2013). Additionally, Cole et al. found that zooplankton has the tendency to ingest polystyrene beads of dimensions 107-30.6 $\mu \mathrm{m}$ (2013). In particular, some copepods like Centropages typicus can ingest enough microplastic that they ultimately lose their feeding abilities (Cole et al., 2013). Microplastics mainly affect planktons indirectly through toxic effects of hazardous chemicals, while nanoplastics are small enough to penetrate cell walls and membranes (Nerland et al., 2014; Besseling et al., 2014).

Benthic species like sea urchins and polychaete ingest microplastics in experimental conditions, while Arenicola marina, a high lipid benthic worm, ingests microplastic particles at the same time as feeding (Nerland et al., 2014). Microplastics are also present in wild mussels and can stay in their digestive system in 48 days following (Moos et al., 2012; Browne et al., 2008). Researchers also found that organisms with gills (like shore crabs) are more vulnerable to microplastics due to the different uptake pathways (Nerland et al., 2014).

For fish, it is known that a fish that accumulates plastics in its gut is more likely to become malnourished and starve, while more information is needed on the translocation of microplastic across the fish gut (Nerland et al., 2014). There are two types of microplastic uptake by fish, active and passive uptake. Active uptake means that fish confuse microplastics with food while passive uptake could mean accidental ingestion during feeding or drinking or transfer within the food chain (Roch et al., 2020). According to Roch et al., microplastics that remain in wild organisms mainly concentrate in the gut (2020). 
Microplastics are also examined in mammalian models, most commonly in mice. Ingested plastics are usually found in the gut, liver, and kidney (Deng et al., 2017; Yang et al., 2019). The gut experiences pathological changes like mucus secretion, gut barrier dysfunction, intestinal inflammation, and gut microbiota dysbiosis (Yong et al., 2020). For mammalian cells, generally, extremely high concentrations of microplastics are cytotoxic and could cause cell death through necrotic plasma membrane rupture (Yong et al., 2020). High concentrations of microplastics could disrupt the lipid bilayer of the plasma membrane while moderate levels could disrupt cellular surface structures like proteoglycans and extracellular matrix components (Yong et et., 2020).

On the human level, microplastic exposure can cause oxidative stress, inflammatory lesions, and increased uptake or translocation. Additionally, there are also potentials for metabolic disturbances, neurotoxicity, and increased cancer risks (Rahman et al., 2021). Microplastics enter the human body through either inhalation or ingestion (Vethaak and Legler, 2021). Limited experiments revealed that only small fractions of administered microplastics are capable of crossing epithelial barriers of lungs and intestines, while uptake efficiency generally increases as particle size decreases (Wright and Kelly, 2017). Although the proportion of particle uptake is relatively low, it is still important because of life-long exposure and accumulation in tissues and organs (Vethaak and Legler, 2021). Young et al. reveals that translocation of microplastics $<10 \mu \mathrm{m}$ from the gut to the lymph and circulatory systems cause systemic exposures and accumulation in tissues like the liver, kidney, and brain (2020). The smallest particles $(<0.1 \mu \mathrm{m})$ may be capable of crossing cell membranes, the placenta, and the brain, therefore, accessing all organs (Young et al., 2020; Gruber et al., 2020; Prüst et al., 2020). Microplastics could cause physical, chemical, and microbiological toxicity when in contact with epithelial linings in the lungs or intestines. In vitro and in vivo rodent studies also indicate the potential of microplastics to cause a variety of biological effects such as physical(particle toxicity, leading to oxidative stress, secretion of cytokines, cellular damage, inflammatory and immune reactions, DNA damage, and neurotoxic and metabolic effects (Young et al., 2020). However, these effects are usually triggered only at high microplastic concentrations and by a combination of particles that are inconsistent with those encountered in the actual environment. Some studies also suggest that aquatic microplastics may act as vectors of microbiological toxicity, carrying biofilm-associated opportunistic bacterial pathogens and antibiotic-resistant genes that interact with the gut microbiota (Lu et al., 2019).

Microplastics, due to their smaller sizes, are easier to be taken up by microorganisms, fish, and other animals (Issac and Kandasubramanian, 2021). They are therefore more likely to be transported through the food chain through bioaccumulation and biomagnification. Additionally, microplastics remain in the environment for a longer period of time due to the difficulties associated with cleanup. Compared to regular plastic, microplastics are more harmful and impactful to organisms (including humans), especially at the cellular level. However, there is also the possibility that microplastics may be degraded by microorganisms, yet the differential rates of biodegradation from these various microorganisms that are capable of breaking down otherwise recalcitrant plastic should be taken into account in the context of commercial applications. Further research is needed to directly compare the difference in impacts of regular plastic versus microplastic for the same type of material.

\section{Conclusions and Perspectives}

Conventional plastics are a central concern to the scientific community today, and much of these recalcitrant polymers are steadily accumulating in both the terrestrial and marine environments. This could have major implications on not only ecological processes but also on human health. Microplastics, in particular, are more persistent in the environment and have greater impacts on organisms. Therefore, studies focusing on introducing renewable plastics through either microbial degradation of commercial-grade polymers or bioproduction of fully degradable plastics must be taken into consideration. It is imperative that we devote effort and resources to better enhance our understanding of these degradation and production rate processes on a metabolic level, so that future plastic production and degradation may be applied on a widely utilized commercial scale. 


\section{Acknowledgments}

I would like to express my gratitude to my advisor Dr. Kartik Chandran for his guidance and mentorship. I want to thank my parents, my brother, and my dogs for their love and support.

\section{References}

Abdel-Motaal, F. F.; El-Sayed, M. A.; El-Zayat, S. A.; Ito, S.-I. Biodegradation of Poly (ع-Caprolactone) (PCL) Film and Foam Plastic by Pseudozyma Japonica Sp. Nov., a Novel Cutinolytic Ustilaginomycetous Yeast Species. 3 Biotech 2014, 4 (5), 507-512. https://doi.org/10.1007/s13205-013-0182-9

Alaerts, L.; Augustinus, M.; Van Acker, K. Impact of Bio-Based Plastics on Current Recycling of Plastics. Sustainability 2018, 10 (5), 1487. https://doi.org/10.3390/su10051487.

Bioplastics market data https://www.european-bioplastics.org/market/.

Beachum, L. Dead Sperm Whale Had 220 Pounds of Garbage in Its Stomach, Including Rope, Plastic and Gloves. The Washington Post. December 2, 2019.

Besseling, E.; Wang, B.; Lürling, M.; Koelmans, A. A. Nanoplastic Affects Growth of S. Obliquus and Reproduction of D. Magna. Environmental Science \& Technology 2014, 48 (20), 12336-12343. https://doi.org/10.1021/es503001d.

Boethling, R. S.; Sommer, E.; DiFiore, D. Designing Small Molecules for Biodegradability. Chemical Reviews 2007, 107 (6), 2207-2227. https://doi.org/10.1021/cr050952t.

Borunda, A. This whale had more than 88 pounds of plastic in its stomach when it died https://www.nationalgeographic.com/environment/2019/03/whale-dies-88-pounds-plastic-philippines/\#close. (accessed Oct 20, 2021).

Browne, M. A.; Dissanayake, A.; Galloway, T. S.; Lowe, D. M.; Thompson, R. C. Ingested Microscopic Plastic Translocates to the Circulatory System of the Mussel,Mytilus Edulis(L.). Environmental Science \& Technology 2008, 42 (13), 5026-5031. https://doi.org/10.1021/es800249a.

Cacciari, I., Quatrini, P., Zirletta, G., Mincione, E., Vinciguerra, V., Lupattelli, P., \& Giovannozzi Sermanni, G. Isotactic polypropylene biodegradation by a microbial community: physicochemical characterization of metabolites produced. Applied and environmental microbiology 1993, 59(11), 3695-3700.

https://doi.org/10.1128/aem.59.11.3695-3700.1993

Chatterjee, Subhankar; Sharma, Shivika. Microplastics in Our Oceans and Marine Health. Field Actions Science Reports. The journal of field actions 2019, No. Special Issue 19, 54-61.

https://doi.org/http://journals.openedition.org/factsreports/5257.

Danso, D.; Chow, J.; Streit, W. R. Plastics: Environmental and Biotechnological Perspectives on Microbial Degradation. Applied and Environmental Microbiology 2019, 85 (19). https://doi.org/10.1128/aem.01095-19. Darby, R. T.; Kaplan, A. M. Fungal Susceptibility of Polyurethanes. Applied Microbiology 1968, 16 (6), 900-905. https://doi.org/10.1128/am.16.6.900-905.1968.

Deng, Y.; Zhang, Y.; Lemos, B.; Ren, H. Tissue Accumulation of Microplastics in Mice and Biomarker Responses Suggest Widespread Health Risks of Exposure. Scientific Reports 2017, 7 (1). https://doi.org/10.1038/srep46687. Di, M.; Wang, J. Microplastics in Surface Waters and Sediments of the Three Gorges Reservoir, China. Science of The Total Environment 2018, 616-617, 1620-1627. https://doi.org/10.1016/j.scitotenv.2017.10.150.

Ebbesen, M. F.; Gerke, C.; Hartwig, P.; Hartmann, L. Biodegradable Poly(Amidoamine)S with Uniform Degradation Fragments via Sequence-Controlled Macromonomers. Polymer Chemistry 2016, 7 (46), $7086-7093$. https://doi.org/10.1039/C6PY01700B. 
Eriksen, M.; Lebreton, L. C. M.; Carson, H. S.; Thiel, M.; Moore, C. J.; Borerro, J. C.; Galgani, F.; Ryan, P. G.; Reisser, J. Plastic Pollution in the World's Oceans: More than 5 Trillion Plastic Pieces Weighing over 250,000 Tons Afloat at Sea. PLoS ONE 2014, 9 (12), e111913. https://doi.org/10.1371/journal.pone.0111913.

Filiciotto, L.; Rothenberg, G. Biodegradable Plastics: Standards, Policies, and Impacts. ChemSusChem 2020,14 (1). https://doi.org/10.1002/cssc.202002044.

Garcia, J. M.; Robertson, M. L. The Future of Plastics Recycling. Science 2017, 358(6365), 870-872. https://doi.org/10.1126/science.aaq0324.

Gewert, B.; Plassmann, M. M.; MacLeod, M. Pathways for Degradation of Plastic Polymers Floating in the Marine Environment. Environmental Science: Processes \& Impacts 2015, 17 (9), 1513-1521. https://doi.org/10.1039/c5em00207a.

Geyer, R.; Jambeck, J. R.; Law, K. L. Production, Use, and Fate of All Plastics Ever Made. Science Advances 2017, 3 (7). https://doi.org/10.1126/sciadv.1700782.

Giacomucci, L.; Raddadi, N.; Soccio, M.; Lotti, N.; Fava, F. Polyvinyl Chloride Biodegradation by Pseudomonas Citronellolis and Bacillus Flexus. N. Biotechnol. 2019, 52, 35-41. https://doi.org/10.1016/j.nbt.2019.04.005.

Goff, M.; Ward, P. G.; O’Connor, K. E. Improvement of the Conversion of Polystyrene to Polyhydroxyalkanoate through the Manipulation of the Microbial Aspect of the Process: A Nitrogen Feeding Strategy for Bacterial Cells in a Stirred Tank Reactor. Journal of Biotechnology 2007, 132 (3), 283-286.

https://doi.org/10.1016/j.jbiotec.2007.03.016.

Gregory, M. R. Environmental Implications of Plastic Debris in Marine Settings-Entanglement, Ingestion, Smothering, Hangers-On, Hitch-Hiking and Alien Invasions. Philosophical Transactions of the Royal Society B: Biological Sciences 2009, 364 (1526), 2013-2025. https://doi.org/10.1098/rstb.2008.0265.

Grothe, E.; Chisti, Y. Poly( $\beta$-Hydroxybutyric Acid) Thermoplastic Production by Alcaligenes Latus: Behavior of Fed-Batch Cultures. Bioprocess Biosyst. Eng. 2000, 22 (5), 441-449. https://doi.org/10.1007/s004490050757. Gruber, M. M.; Hirschmugl, B.; Berger, N.; Holter, M.; Radulović, S.; Leitinger, G.; Liesinger, L.; Berghold, A.; Roblegg, E.; Birner-Gruenberger, R.; Bjelic-Radisic, V.; Wadsack, C. Plasma Proteins Facilitates Placental Transfer of Polystyrene Particles. Journal of Nanobiotechnology 2020, 18 (1). https://doi.org/10.1186/s12951-020-00676-5. Harrison, J. P.; Sapp, M.; Schratzberger, M.; Osborn, A. M. Interactions between Microorganisms and Marine Microplastics: A Call for Research. Marine Technology Society Journal 2011, 45 (2), 12-20. https://doi.org/10.4031/mtsj.45.2.2.

Ikura, Y.; Kudo, T. Isolation of a Microorganism Capable of Degrading Poly-(L-Lactide). J. Gen. Appl. Microbiol. 1999, 45 (5), 247-251. https://doi.org/10.2323/jgam.45.247.

Issac, M. N.; Kandasubramanian, B. Effect of Microplastics in Water and Aquatic Systems. Environ. Sci. Pollut. Res. Int. 2021, 28 (16), 19544-19562.

Jambeck, J. R.; Geyer, R.; Wilcox, C.; Siegler, T. R.; Perryman, M.; Andrady, A.; Narayan, R.; Law, K. L. Plastic Waste Inputs from Land into the Ocean. Science 2015, 347 (6223), 768-771.

https://doi.org/10.1126/science.1260352.

Jeon, H. J.; Kim, M. N. Isolation of a Thermophilic Bacterium Capable of Low-Molecular-Weight Polyethylene Degradation. Biodegradation 2013, 24(1), 89-98. ～https://doi.org/10.1007/s10532-012-9560-y

Kale, S.; Keshmukh, A. G.; Dudhare, M.; Patil, V. Microbial Degradation of Plastic - a Review. International Journal of Pharmaceutical Research 2020, 13 (01). https://doi.org/10.31838/ijpr/2021.13.01.245.

Karan, H.; Funk, C.; Grabert, M.; Oey, M.; Hankamer, B. Green Bioplastics as Part of a Circular Bioeconomy. Trends in Plant Science 2019, 24 (3), 237-249. https://doi.org/10.1016/j.tplants.2018.11.010.

Kaufman, H. No Such Place As “Away": Plastic Pollution in the Oceans, Why We Should Care, and What to Do About It | InterAction Council https:/www.interactioncouncil.org/publications/no-such-place-away-plasticpollution-oceans-why-we-should-care-and-what-do-about-it. 
Kolvenbach, B. A.; Helbling, D. E.; Kohler, H.-P. E.; Corvini, P. F-X. Emerging Chemicals and the Evolution of Biodegradation Capacities and Pathways in Bacteria. Current Opinion in Biotechnology 2014, $27,8-14$. https://doi.org/10.1016/j.copbio.2013.08.017. Kunioka, M.; Ninomiya, F.; Funabashi, M. Biodegradation of Poly(Butylene Succinate) Powder in a Controlled Compost at $58{ }^{\circ} \mathrm{c}$ Evaluated by Naturally-Occurring Carbon 14 Amounts in Evolved CO2 Based on the ISO 148552 Method. International Journal of Molecular Sciences 2009, 10 (10), 4267-4283. https://doi.org/10.3390/ijms10104267.

Li, C.; Gan, Y.; Dong, J.; Fang, J.; Chen, H.; Quan, Q.; Liu, J. Impact of Microplastics on Microbial Community in Sediments of the Huangjinxia Reservoir-Water Source of a Water Diversion Project in Western China.

Chemosphere 2020, 253, 126740. https://doi.org/10.1016/j.chemosphere.2020.126740.

Liu, G.; Jiang, R.; You, J.; Muir, D. C. G.; Zeng, E. Y. Microplastic Impacts on Microalgae Growth: Effects of Size and Humic Acid. Environmental Science \& Technology 2019, 54 (3), 1782-1789.

https://doi.org/10.1021/acs.est.9b06187.

Lovett, J.; de Bie, F. SUSTAINABLE SOURCING of FEEDSTOCKS for BIOPLASTICS; 2016.

Lu, L.; Luo, T.; Zhao, Y.; Cai, C.; Fu, Z.; Jin, Y. Interaction between Microplastics and Microorganism as Well as Gut Microbiota: A Consideration on Environmental Animal and Human Health. Science of The Total Environment 2019, 667, 94-100. https://doi.org/10.1016/j.scitotenv.2019.02.380.

Luo, K.; Yang, J.; Kopečková, P.; Kopeček, J. Biodegradable Multiblock Poly[N-(2-Hydroxypropyl)Methacrylamide] via Reversible Addition-Fragmentation Chain Transfer Polymerization and Click Chemistry. Macromolecules 2011, 44 (8), 2481-2488. https://doi.org/10.1021/ma102574e.

Machmud, M. N.; Fahmi, R.; Abdullah, R.; Kokarkin, C. Characteristics of Red Algae Bioplastics/Latex Blends under Tension. International Journal of Science and Engineering 2013, 5 (2). https://doi.org/10.12777/ijse.5.2.81-88. Mohanan, N.; Montazer, Z.; Sharma, P. K.; Levin, D. B. Microbial and Enzymatic Degradation of Synthetic Plastics. Frontiers in Microbiology 2020, 11. https://doi.org/10.3389/fmicb.2020.580709.

Mor, R.; Sivan, A. Biofilm Formation and Partial Biodegradation of Polystyrene by the Actinomycete Rhodococcus Ruber: Biodegradation of Polystyrene: Biodegradation of Polystyrene. Biodegradation 2008, 19 (6), 851-858. Mughini-Gras, L.; van der Plaats, R. Q. J.; van der Wielen, P. W. J. J.; Bauerlein, P. S.; de Roda Husman, A. M. Riverine Microplastic and Microbial Community Compositions: A Field Study in the Netherlands. Water Research 2021, 192, 116852. https://doi.org/10.1016/j.watres.2021.116852.

Murphy, S. H.; Leeke, G. A.; Jenkins, M. J. A Comparison of the Use of FTIR Spectroscopy with DSC in the Characterisation of Melting and Crystallisation in Polycaprolactone. Journal of Thermal Analysis and Calorimetry 2011, 107 (2), 669-674. https://doi.org/10.1007/s10973-011-1771-7.

NOAA. What are microplastics? https:/oceanservice.noaa.gov/facts/microplastics.html.

Nakajima-Kambe, T.; Onuma, F.; Kimpara, N.; Nakahara, T. Isolation and Characterization of a Bacterium Which Utilizes Polyester Polyurethane as a Sole Carbon and Nitrogen Source. FEMS Microbiol. Lett. 1995, 129 (1), 39-42. https://doi.org/10.1016/0378-1097(95)00131-n

Nakanishi, A.; Iritani, K.; Sakihama, Y. Developing Neo-Bioplastics for the Realization of Carbon Sustainable Society. Journal of Nanotechnology and Nanomaterials 2020, 1 (2). https://doi.org/10.33696/Nanotechnol.1.010.

Okey, R. W.; Stensel, H. David. A QSAR-Based Biodegradability Model—a QSBR. Water Research 1996, 30 (9), 2206-2214. https://doi.org/10.1016/0043-1354(96)00098-X.

Onen Cinar, S.; Chong, Z. K.; Kucuker, M. A.; Wieczorek, N.; Cengiz, U.; Kuchta, K. Bioplastic Production from Microalgae: A Review. International Journal of Environmental Research and Public Health 2020, 17 (11), 3842. https://doi.org/10.3390/ijerph17113842.

Parker, L. Plastic pollution facts and information https://www.nationalgeographic.com/environment/article/plasticpollution. 
Perotto, G.; Ceseracciu, L.; Simonutti, R.; Paul, U. C.; Guzman-Puyol, S.; Tran, T.-N.; Bayer, I. S.; Athanassiou, A. Bioplastics from Vegetable Waste via an Eco-Friendly Water-Based Process. Green Chemistry 2018, 20 (4), 894902. https://doi.org/10.1039/c7gc03368k.

Preusting, H.; Hazenberg, W.; Witholt, B. Continuous Production of Poly(3-Hydroxyalkanoates) by Pseudomonas Oleovorans in a High-Cell-Density, Two-Liquid-Phase Chemostat. Enzyme Microb. Technol. 1993, 15 (4), $311-316$. https://doi.org/10.1016/0141-0229(93)90156-V.

Prüst, M.; Meijer, J.; Westerink, R. H. S. The Plastic Brain: Neurotoxicity of Micro- and Nanoplastics. Particle and Fibre Toxicology 2020, 17 (1). https://doi.org/10.1186/s12989-020-00358-y.

Rahman, A.; Sarkar, A.; Yadav, O. P.; Achari, G.; Slobodnik, J. Potential Human Health Risks due to Environmental Exposure to Nano- and Microplastics and Knowledge Gaps: A Scoping Review. Science of The Total Environment 2021, 757, 143872. https://doi.org/10.1016/j.scitotenv.2020.143872.

Reed, C. Plastic Age: How it's reshaping rocks, oceans and life https://www.newscientist.com/article/mg22530060200-plastic-age-how-its-reshaping-rocks-oceans-and-life/.

Roch, S.; Friedrich, C.; Brinker, A. Uptake Routes of Microplastics in Fishes: Practical and Theoretical Approaches to Test Existing Theories. Scientific Reports 2020, 10 (1), 1-12. https://doi.org/10.1038/s41598-020-60630-1.

Rogers, K. L.; Carreres-Calabuig, J. A.; Gorokhova, E.; Posth, N. R. Micro-By-Micro Interactions: How Microorganisms Influence the Fate of Marine Microplastics. Limnology and Oceanography Letters 2020, 5 (1), 18-36. https://doi.org/10.1002/lol2.10136.

Royer, S.-J.; Ferrón, S.; Wilson, S. T.; Karl, D. M. Production of Methane and Ethylene from Plastic in the Environment. PLOS ONE 2018, 13 (8), e0200574. https://doi.org/10.1371/journal.pone.0200574.

Sanin, S. L.; Sanin, F. Dilek.; Bryers, J. D. Effect of Starvation on the Adhesive Properties of Xenobiotic Degrading Bacteria. Process Biochemistry 2003, 38 (6), 909-914. https://doi.org/10.1016/s0032-9592(02)00173-5.

Seeley, M. E.; Song, B.; Passie, R.; Hale, R. C. Microplastics Affect Sedimentary Microbial Communities and Nitrogen Cycling. Nature Communications 2020, 11 (1). https://doi.org/10.1038/s41467-020-16235-3.

Shah, A. A.; Kato, S.; Shintani, N.; Kamini, N. R.; Nakajima-Kambe, T. Microbial Degradation of Aliphatic and Aliphatic-Aromatic Co-Polyesters. Applied Microbiology and Biotechnology 2014, 98 (8), 3437-3447. https://doi.org/10.1007/s00253-014-5558-1.

Sivan, A.; Szanto, M.; Pavlov, V. Biofilm Development of the Polyethylene-Degrading Bacterium Rhodococcus Ruber. Applied Microbiology and Biotechnology 2006, 72 (2), 346-352. https://doi.org/10.1007/s00253-005-0259-4. Suzuki, K.; Mikami, T.; Okawa, Y.; Tokoro, A.; Suzuki, S.; Suzuki, M. Antitumor Effect of Hexa-N-Acetylchitohexaose and Chitohexaose. Carbohydr. Res. 1986, 151, 403-408. https://doi.org/10.1016/s00086215(00)90359-8

Tokiwa, Y.; Calabia, B.; Ugwu, C.; Aiba, S. Biodegradability of Plastics. International Journal of Molecular Sciences 2009, 10 (9), 3722-3742. https://doi.org/10.3390/ijms10093722.

Tsang, J. Changing CO2 Levels Require Microbial Coping Strategies https://asm.org/Articles/2019/April/ChangingCO2-Levels-Means-Different-Coping-Strateg.

Vethaak, A. D.; Legler, J. Microplastics and Human Health. Science 2021, 371 (6530), 672-674. https://doi.org/10.1126/science.abe5041.

Wei, R.; Zimmermann, W. Microbial Enzymes for the Recycling of Recalcitrant Petroleum-Based Plastics: How Far Are We? Microbial Biotechnology 2017, 10 (6), 1308-1322. https://doi.org/10.1111/1751-7915.12710.

Wilkes, R. A.; Aristilde, L. Degradation and Metabolism of Synthetic Plastics and Associated Products ByPseudomonassp.: Capabilities and Challenges. Journal of Applied Microbiology 2017, 123 (3), 582-593.

https://doi.org/10.1111/jam.13472.

Wright, S.; Kelly, F. Plastic and Human Health: A Micro Issue? https://scholar.google.com/scholar?q=\%2C+Environ.+Sci.+Technol.+51\%2C+6634+\%282017\%29. (accessed Oct 20, 2021). 
Wu, B.; Wu, X.; Liu, S.; Wang, Z.; Chen, L. Size-Dependent Effects of Polystyrene Microplastics on Cytotoxicity and Efflux Pump Inhibition in Human Caco-2 cells. Chemosphere 2019, 221, 333-341.

https://doi.org/10.1016/j.chemosphere.2019.01.056.

Yang, Y.-F.; Chen, C.-Y.; Lu, T.-H.; Liao, C.-M. Toxicity-Based Toxicokinetic/Toxicodynamic Assessment for Bioaccumulation of Polystyrene Microplastics in Mice. Journal of Hazardous Materials 2019, 366, 703-713.

https://doi.org/10.1016/j.jhazmat.2018.12.048.

Yong, C. Q. Y.; Valiyaveetill, S.; Tang, B. L. Toxicity of Microplastics and Nanoplastics in Mammalian Systems. International Journal of Environmental Research and Public Health 2020, 17 (5), 1509. https://doi.org/10.3390/ijerph17051509.

Zhao, J.-H.; Wang, X.-Q.; Zeng, J.; Yang, G.; Shi, F.-H.; Yan, Q. Biodegradation of Poly(Butylene Succinate) in Compost. J. Appl. Polym. Sci. 2005, 97 (6), 2273-2278. https://doi.org/10.1002/app.22009.

Zettler, E. R.; Mincer, T. J.; Amaral-Zettler, L. A. Life in the "Plastisphere": Microbial Communities on Plastic Marine Debris. Environmental Science \& Technology 2013, 47 (13), 7137-7146. https://doi.org/10.1021/es401288x. van Sebille, E.; Wilcox, C.; Lebreton, L.; Maximenko, N.; Hardesty, B. D.; van Franeker, J. A.; Eriksen, M.; Siegel, D.; Galgani, F.; Law, K. L. A Global Inventory of Small Floating Plastic Debris. Environmental Research Letters 2015, 10 (12), 124006. https://doi.org/10.1088/1748-9326/10/12/124006.

von Moos, N.; Burkhardt-Holm, P.; Köhler, A. Uptake and Effects of Microplastics on Cells and Tissue of the Blue Mussel Mytilus Edulis L. After an Experimental Exposure. Environmental Science \& Technology 2012, 46 (20), 11327-11335. https://doi.org/10.1021/es302332w. 